\title{
Integration of VR with BIM to facilitate real-time creation of bill of quantities during the design phase: A proof of concept study
}

(C) The Author(s) 2020. This article is published with open access at link.springer.com and journal.hep.com.cn

\begin{abstract}
As building practices change, procedures that seemed indispensable at one point can be abandoned for others, one example of which is the bill of quantities (B/Q). Research into the extant literature attributes the declining use of $\mathrm{B} / \mathrm{Qs}$ to a multitude of reasons, such as its complexity, the potentially long time required to produce it, the growth in popularity of non-traditional procurement systems, and the challenge of using the information within the document in a construction schedule. With these issues in mind, building information modeling (BIM) and virtual reality (VR) are combined and proposed as a potential solution that allows inclusion of the client into the design process. Following a literature review and precedent study, an experiment was carried out using this new process to simulate a client's design decisions on window and interior furnishings. The choices made by the client using VR automatically updated a B/Q schedule built in Revit and allowed them to have a firm understanding of project costs. Besides giving the client more confidence in a pleasing final outcome, the technology also ensured an up-to-date, accurate, and easily understandable $\mathrm{B} / \mathrm{Q}$. The proposed method features great potential savings in cost and time and gives the $\mathrm{B} / \mathrm{Q}$ a newfound importance in future construction processes. The research case presented in this paper is a stepping stone in exploring new opportunities
\end{abstract}

Received March 14, 2019; accepted April 1, 2019

Jordan DAVIDSON, John FOWLER, Charalampos PANTAZIS, Massimo SANNINO, Jordan WALKER

Department of Architecture, University of Strathclyde, Glasgow G1 1XJ, UK

Moslem SHEIKHKHOSHKAR, Farzad Pour RAHIMIAN ( Department of Mechanical and Construction Engineering, Faculty of Engineering and Environment, Northumbria University, Newcastle NE1 8ST, UK

E-mail: farzad.rahimian@northumbria.ac.uk

Open access funding provided by Northumbria University. offered by VR and BIM and how they could improve the reliability and accuracy of traditional procurement within construction, specifically within the B/Q document.

Keywords virtual reality, bill of quantities, BIM, Revit, real-time synchronisation

\section{Introduction}

In the construction project domain, a large number of documents, for example, contracts, tenders, and control execution, are essential to support different management tasks. One of the most relevant documents in this domain is the bill of quantities (B/Q) (Martínez-Rojas et al., 2016). The $\mathrm{B} / \mathrm{Q}$ document was introduced in the UK during the 19 th century. At the time of its introduction, the B/Q was used by tradesmen to pay their workers and request fees from clients. Today, it has evolved to specify the qualitative and quantitative aspects of every element of a proposed project and essentially forms a record of all of the items used in construction (Rashid et al., 2006).

The $\mathrm{B} / \mathrm{Q}$ document, as a significant component of a tender document, is still commonly used to estimate costs as part of the traditional procurement process. However, recent data suggest that the use of this document type is gradually declining due to a variety of reasons, such as its complicated and time-consuming preparation, the increase in the use of non-traditional procurement systems, and difficulties associated with incorporating its information into a real-life construction schedule (Odeyinka and Perera, 2009; Bandi et al., 2014; Razali et al., 2014). The $\mathrm{B} / \mathrm{Q}$ document attempts to supply comprehensive cost information to clients; however, as a project progresses, costs often increase and the $\mathrm{B} / \mathrm{Q}$ is not updated (Rashid et al., 2006). This issue can cause a client to feel uninformed about how their money is being used and the 
overall financial position of the project.

Over the last two decades, the architecture, engineering, construction, and facility management industry has witnessed a steady increase in interest in virtual reality (VR) to improve existing work processes (Wang and Schnabel, 2008). Especially when integrated with building information modeling (BIM), VR offers a semantically rich visualization method to help users intuitively understand the design environment in a fully immersive manner (Donalek et al., 2014), thus allowing all stakeholders to be involved during all stages of design and decision making (Rahimian et al., 2019). As an appealing multimedia technology, VR creates enriched virtual environments that allow users to interact with digital objects in real time (Warwick et al., 1993). It has been used to address a variety of construction projects problems, including design coordination (Messner et al., 2003), construction operations coordination (Bouchlaghem et al., 2005), facility management (Shi et al., 2016), and real estate (Chen, 1995). VR provides new perspectives for designers to visualize their design through an immersive experience (Weidlich et al., 2007).

This paper takes advantage of this technology by investigating the use BIM and VR as a means of further involving clients in design decisions and creating an improved B/Q process. Focusing on aesthetic choices, such as the size and position of windows and interior furnishings, will illustrate VR's capacity to improve the design process and better satisfy clients' desires. Moreover, as the client makes these choices, they will have direct access to an updated $\mathrm{B} / \mathrm{Q}$ and fully understand the costs involved. This technology aims to modernize the $\mathrm{B} / \mathrm{Q}$ process and convert a potentially complex document into an accessible and interactive user experience.

\section{Bill of quantities}

The B/Q plays a supporting role in project documentation and is designed to tally costs. Requirement for a $\mathrm{B} / \mathrm{Q}$ as part of the project documentation and a $\mathrm{B} / \mathrm{Q}$ as the basis for an investor's cost estimate allow not only differences in the way of describing the $\mathrm{B} / \mathrm{Q}$ basis and consequently costing, but also in terms of the material scope taken into account in those documents (Zima, 2017).

In early design stages, the $\mathrm{B} / \mathrm{Q}$ provides a list of detailed work descriptions and quantities, as well as the tasks that must be performed, to ensure a successful project; this document enables contractors to prepare tenders efficiently and accurately. During the post-tender stage, the B/Q provides a basis for controlling different work and cost plans and appraising the executed work to facilitate payments to the contractor (Nadeem et al., 2015). The $\mathrm{B} / \mathrm{Q}$ has been used for roughly the same purpose for centuries; today, several technological and methodological advancements have improved the efficiency and accuracy of the document.

Introduction to $\mathrm{CAD} / \mathrm{CAE}$ systems in the 1950 is one example of a technical improvement the $\mathrm{B} / \mathrm{Q}$ has been subject to (Olatunji, 2011). Today, the widespread adoption of BIM and VR systems in the construction industry has prompted a review of the preparation, use, functionality, and efficiency of the $\mathrm{B} / \mathrm{Q}$. The document is still often used within the construction industry, particularly in traditionally procured schemes, where it continues to provide cost estimates for clients, and forms part of the tender document used by speculative contractors to price, program, and bid for a potential contract (Rashid et al., 2006).

Recently, however, traditionally procured schemes have seen a decline in use, particularly as they are being replaced by more modern contract systems, such as design and build or management contracting, thus often forgoing the need for a $\mathrm{B} / \mathrm{Q}$. These procurement systems present several benefits over traditional procurement, for example, by reducing the tender and design stages, while also minimizing the financial risk of clients. A tender can be condensed by modern procurement methods, partly by removing the need to prepare a $\mathrm{B} / \mathrm{Q}$, which is often a lengthy and onerous process (Davis et al., 2009). Modern procurement methods can give clients a degree of cost certainty that is not feasible with traditional procurement; this enhanced level of certainty is usually achieved-such as in design and build-by giving the contractor greater control over the design of a project, although potential financial risks are also transferred to the same(Davis et al., 2009). Contemporary procurement methods are not appropriated in all schemes, however; smaller unique projects where control over the design is the preeminent concern are still best served by the traditional contract route. The Royal Institute of British Architects (RIBA) Plan of Work 2013 overview reinforces the continued importance of traditional contracts by pointing out that this procurement method remains by far the most dominant form of procurement (Sinclair, 2013). Therefore, the production and quality of the $\mathrm{B} / \mathrm{Q}$ must continue to be refined as it is vital to the traditional procurement system.

As B/Qs are regularly used in tender documents, a poorquality $\mathrm{B} / \mathrm{Q}$ can seriously undermine the validity of tenders and lead to inaccurate estimates, higher margins in bids, and claims and disputes (Laryea, 2011). A B/Q is typically produced by a qualified quantity surveyor, who bases the document on specifications and drawings produced by the architect (Odeyinka and Perera, 2009). Therefore, as the B/ $\mathrm{Q}$ is directly derived from architects' schedules and drawings, the document is vulnerable to a client's oversight or misunderstanding of elements proposed within schedules and drawings. Elements such as interior finishes, carpentry, and ironmongery are particularly susceptible to oversight as the client can find it difficult to visualize these components. These oversights and misunderstandings must be fixed later and are often discovered only after construction has begun, leading to on-site alterations and 
increased costs. This issue is described by $\mathrm{Li}$ and Love (1998), who found that a significant proportion of rework in construction is caused by last-minute changes by the client and their inability to acquire a realistic appreciation of the product from 2D drawings at the design stage.

If a client cannot gain a realistic understanding of the typical 2D drawings and schedules presented by an architect, which is the basis of the $\mathrm{B} / \mathrm{Q}$, before the tender stage, the accuracy of the document can be undermined. The accuracy of a B/Q can be improved by clearly demonstrating to the client what exactly is in the document before it is finalized ( $\mathrm{Li}$ and Love, 1998). $\mathrm{Li}$ and Love (1998) proposed a solution to this issue, which they believe is caused by the presentation of a building's design in 2D format; the scholars created a 3D visualization system that allowed clients to "walk through" a design so that they can gain an appreciation of the interior layout and its architectural details in VR. This feature allows clients to suggest changes to the design before it is "quantified" into a B/Q and improves the accuracy of the document as it closely reflects the client's desires in a project; it would also reduce "last-minute" client changes that may incur extra costs. Thus, Li and Love (1998) concluded that the walk-through provides significant advantages over standard 2D drawings.

\section{Study framework}

Motivated by this theoretical background, the present study aims to explore new opportunities offered by VR and BIM and how they could improve the reliability and accuracy of traditional procurement within construction, specifically within the $\mathrm{B} / \mathrm{Q}$ document. As such, a proof of concept of a working prototype is developed in several stages: (1) The BIM model and B/Qs are created, (2) the model is converted into $\mathrm{VR},(3)$ designing and building are conducted in VR, (4) the interactive design is presented, and (5) a precedent study is performed (Fig. 1).

The BIM model utilized for this prototype is a private detached house previously designed by one of the authors. The model is considered highly appropriate for the present use due to the fact that its typology offers a close connection between architect and client; specifically, it demands greater and more personal involvement from the client than other building types. A great deal of care is

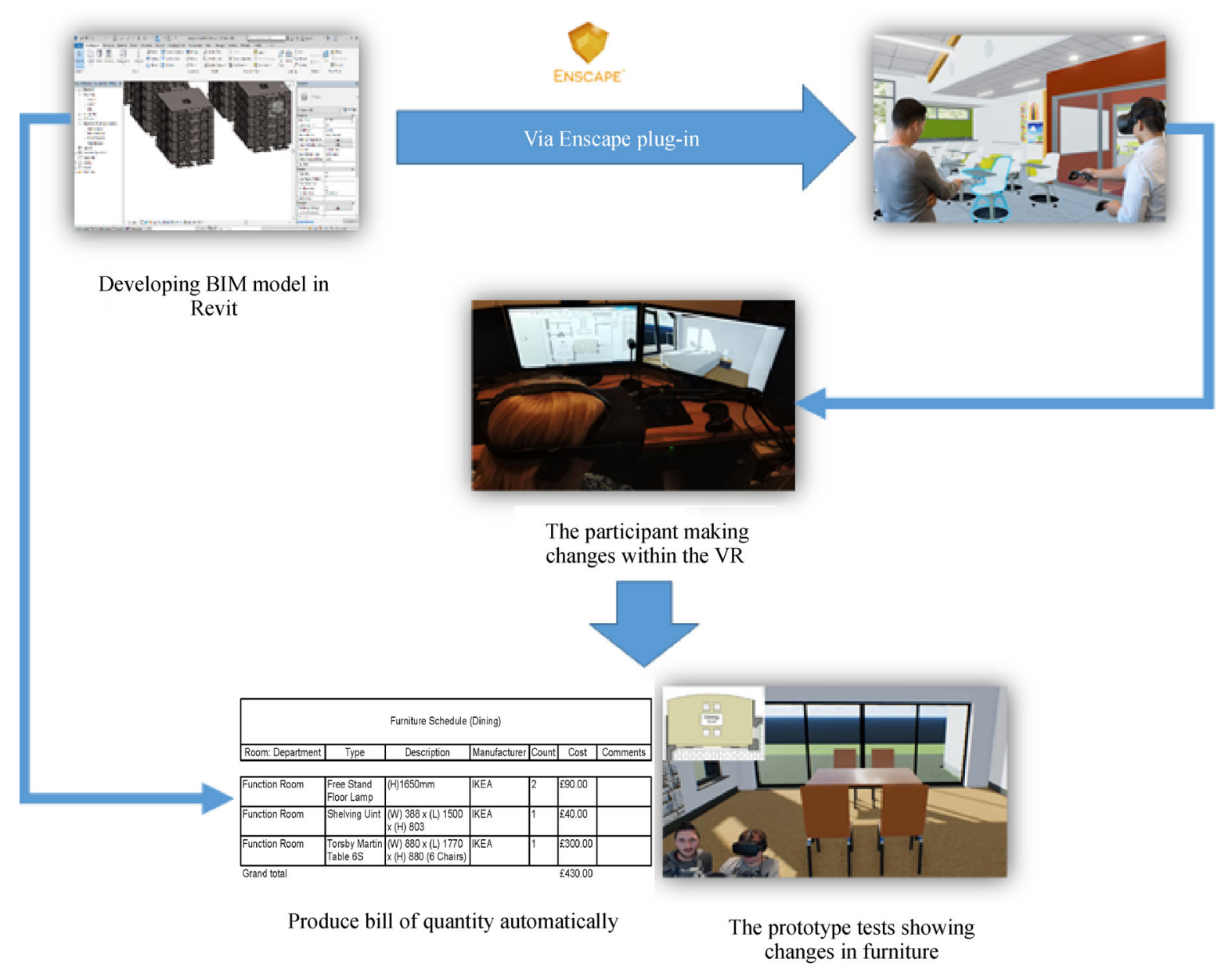

Fig. 1 Framework of the prototype 
exerted when attempting to identify a client's favored decorations and detailing to perfect their home, and VR can be exceptionally helpful in this circumstance. Each design choice can have a considerable effect on the oftenlow budget of most residential projects, which gives $\mathrm{B} / \mathrm{Qs}$ increased significance. The window types and furnishings used in the model were compiled from the building information supplied by building contractors and manufacturers' Revit packs. The data from each architectural element were then automatically included into a Revit schedule, which computes pricing.

To move the model into VR, different strategies were considered. Bille et al. (2014) explained that a typical work process involves finishing a model in Revit, changing over into another graphing software, such as $3 \mathrm{~d}$ s Max, and then loading the resulting FBX file into a gaming engine, such as Unreal Engine or Stingray. The team noted that, during this complex and tedious process, data are commonly lost. In addition, no synchronization with updated models is available, which means if the model is updated in Revit, the entire procedure must be carried out once more (Du et al., 2018). This repetition is counter-intuitive to the iterative design process involved in architecture - a field where exchange of feedback and notification of small changes to be made are commonplace and constant.

To solve this problem, the study explored research currently being developed to address the swift translation of CAD/BIM to VR (Lorenz et al., 2016; Petrova et al., 2017; Du et al., 2018). After examining the available methods, this paper selected the Enscape plugin, which suits the prototype's needs best because the software works seamlessly with programs like Revit to produce real-time and fully navigable VR (Corke, 2017). With one click, the drawing information is quickly converted into VR without losing any information. This feature fully resolves the previously mentioned problems of time and complexity. Furthermore, Enscape is especially well-suited for dealing with the synchronization issue. Any alterations made to the linked Revit model are updated automatically by the software, which allows clients to gain an improved understanding of their design and any possible changes to be made; it also removes potential unpleasant surprises as the project is constructed. Enscape offers the client a true, life-like, and dynamic imitation of a planned space that is much easier to understand than an abstracted 2D drawing.

The presentation is a vital piece of the architectural process. Client presentations must be clear, and a smooth portrayal of the design solution is required to earn the client's approval. Utilizing a range of software here can markedly improve design presentations. The combination of Revit for modeling and Enscape for visualization gives the design team the ability to make changes in real time and makes any design work simple for clients to comprehend. Enscape updates the design and conveys to the client exactly how the project looks and how different objects sit in space. This presentation method grants immediate implementation into a workflow and can save time and money.

The final stage involved completion of a precedent study using the currently available software. Researching VR building showroom applications was very rewarding since an increasing number of companies and manufacturers now use VR to illustrate how their product can be customized or sits within a room or place. Unfortunately, the available applications clearly had a limited scope. For instance, the IKEA showroom portrays what products from their catalog look like and how they fit into a room with a VR $360^{\circ}$ camera orientation; however, the room is not tailored to the client's specifications and the price of each item is not shown (Agency, 2018). The Zerolight and Design Milk showrooms for Audi and Cadillac, for example, give customers a full customization of the vehicles and are some of the most detailed VR applications currently available; however, they do not provide a costing breakdown (ZeroLight, 2018). Thus, the available applications appear to provide an incomplete service that could be enhanced for a superior customer experience. VR showrooms should offer solid visuals demonstrating what the customer is purchasing and variations of the item in different environments, colors, and sizes while also providing the client with accurate pricing. This paper will now describe the proposed prototype and the process of developing it.

\section{Prototype development}

During the development strategy, five key stages in prototype development were identified, as detailed in the previous section, to help clients gain better knowledge of their design scheme and visually grasp what they require for their building within the BIM model. This knowledge, in turn, can be developed into a B/Q through which the client is made fully liable for their decisions. The furniture catalog used to support the development of the BIM prototype and allow the project to feature $3 \mathrm{D}$ models directly into the Revit model was that of IKEA. To create the product catalog for the corresponding BIM models, the following information was required: room department, furniture type, size, manufacturer, count, and cost. Information on room department allowed the project to determine in which room the furniture should be placed, while furniture type indicates the brand of each furniture, such as TORSBY and KALLAX - these brands have various furnishings of the same name however the models this study acquired are based on the actual items used, instead of the brand name. The sizes reflect the dimensions of each piece of furniture, the manufacturers used were IKEA and Magnet Kitchens, the count tells the client how 
many of each product is used within a room department, and the cost is the catalog cost from the manufacturer. This process changed during window modeling, which was originally named based on the manufacturer's specifications. All of the information gathered for the BIM models was developed into specific window types to use within the prototype (JELD-WEN, 2000). The specifications were broken down into window types, which included circular, sash, and casement. Other information required for this task included count, floor level of the window, manufacturer, size, and cost. The BIM model prototype designed in Revit was directed through Enscape, which runs in realtime with Revit and provides live updates from Revit to VR environment. Enscape was used to illustrate VR in key areas created within the prototype model.

The prototype was developed with the associated rooms, such as the living room, dining room, and bedroom, and allowed us to place windows and furniture freely in the available space. For the purpose of testing the prototype, two members of the research team played the role of architect and client; however, a number of errors occurred. For example, due to issues with the Oculus Rift VR Headset software, the project entailed multiple steps of debugging and troubleshooting before the model could be added to the VR environment. Once the user put the headset on, s/he gained a fully immersive experience that had to be tweaked as the movement speed of the controller's analog stick gave the user motion sickness and was, thus, deemed unusable. The user's height had to be referenced in the software so that the user does not feel out of proportion while exploring the space in VR. A recording software was utilized to capture real-time results. After several attempts to change furniture types, the software used to record results crashed mid-testing.

The rooms constructed within the Revit model for testing included a living room, dining room, and bedroom, all of which provided different entries to the $\mathrm{B} / \mathrm{Q}$ schedules for furniture and windows. The living room had furniture and windows divided into the appropriate $\mathrm{B} / \mathrm{Q}$ schedules, while the dining room and bedroom only focused on furniture B/Q schedules. The client could amend, revise, or alter chosen furniture within the allocated room, and the custom-made B/Q schedule was updated live when changes were made by the participant in the test rooms, as shown in Fig. 2.

The B/Q schedules obtained from these rooms included those for windows and furniture; these schedules could then be transferred to members of the design team, such as the contractor, as seen in Figs. 3 and 4.

The results of changes within the rooms done live through Revit were obtained from the recorded videos to check whether the B/Q schedule would correctly add up new costs and remove them when appropriate. This step enabled a $\mathrm{B} / \mathrm{Q}$ to be generated based on changes the client made to the model, as seen in Fig. 5. The connection between the client understanding the idea within the headset and the architect demonstrating changes live within that test improved their relationship, as seen in Fig. 6. The recordings demonstrate that the prototype works and provides a number of benefits, such as $\mathrm{B} / \mathrm{Q}$ accuracy and the clients' approval at various stages, such as feasibility. In terms of contractor costs, the $\mathrm{B} / \mathrm{Q}$ provided by the prototype could be used to obtain an accurate final cost for the proposed build. A cost breakdown where the corresponding schedules highlight each room separately and generate an overall cost per room can be generated. This feature can be made more manageable for clients or contractors to foresee overpayments within each of the rooms. Instead, the contractor valuing the $\mathrm{B} / \mathrm{Q}$ of the approved warrant drawings and providing an estimated value of works can address the $\mathrm{B} / \mathrm{Q}$ schedules that can be provided to the contractor with fixed price of each component.

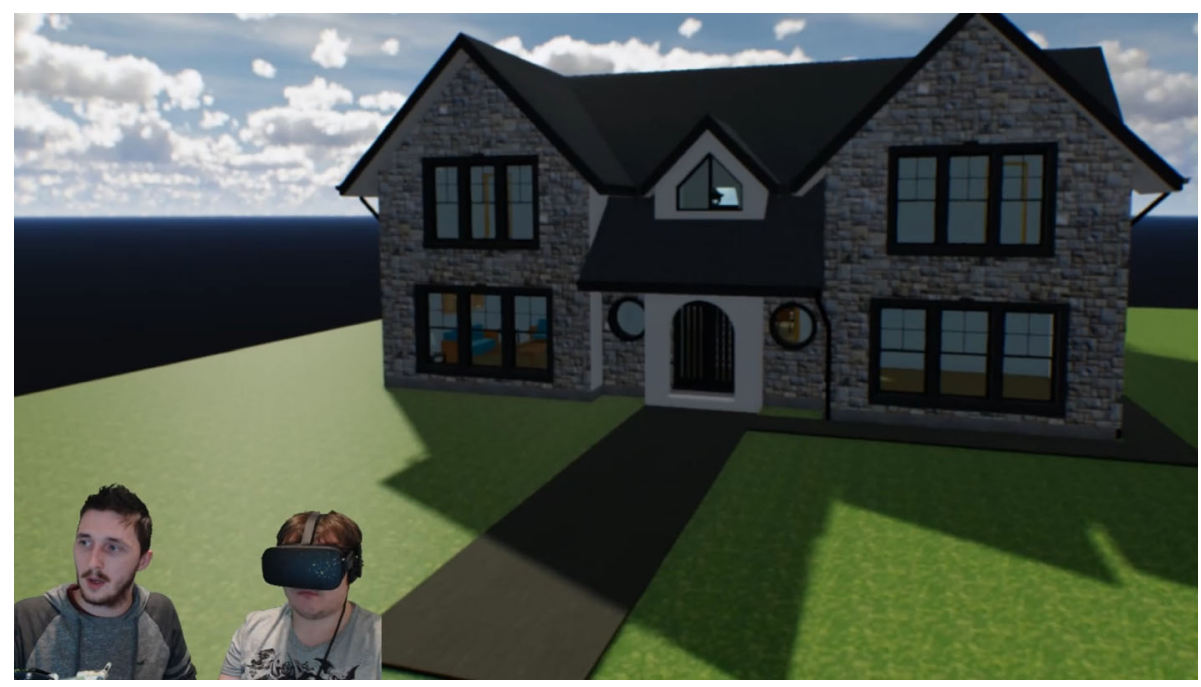

Fig. 2 Revit model immersed in VR 


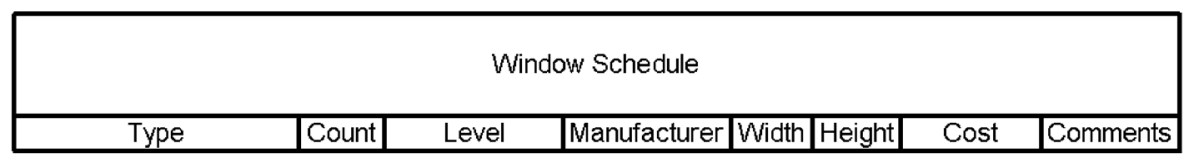

\begin{tabular}{|l|l|l|l|l|l|l|l|}
\hline $\begin{array}{l}\text { Circle Window - } \\
600 \mathrm{~mm} \text { Diameter }\end{array}$ & 1 & 00 Floor Level & Glass Tops & 600 & & $£ 70.00$ & \\
\hline $\begin{array}{l}\text { Circle Window - } \\
\text { 900mm Diameter }\end{array}$ & 1 & 00 Floor Level & Glass Tops & 900 & & $£ 80.00$ & \\
\hline $\begin{array}{l}\text { Sash Window - 900 x } \\
1200 \mathrm{~mm}\end{array}$ & 1 & 00 Floor Level & Glass Tops & 900 & 1200 & $£ 1140.00$ & \\
\hline $\begin{array}{l}\text { Sash Window (Vintage) } \\
-850 x 1850 \mathrm{~mm}\end{array}$ & 4 & 00 Floor Level & $\begin{array}{l}\text { Jeld Wen } \\
\text { Windows \& } \\
\text { Doors }\end{array}$ & 850 & 1850 & $£ 5400.00$ & \\
\hline $\begin{array}{l}\text { Sash Window (Vintage) } \\
-1000 x 1850 \mathrm{~mm}\end{array}$ & 6 & 00 Floor Level & $\begin{array}{l}\text { Jeld Wen } \\
\text { Windows \& } \\
\text { Doors }\end{array}$ & 1000 & 1850 & $£ 9420.00$ & \\
\hline
\end{tabular}

Fig. 3 Sample window schedule

\begin{tabular}{|c|c|c|c|c|c|}
\hline \multicolumn{6}{|c|}{ Furniture Schedule (Dining) } \\
\hline Room: Department & Type & Description & \begin{tabular}{|l|l|} 
Manufacturer & Count \\
\end{tabular} & Cost & Comments \\
\hline
\end{tabular}

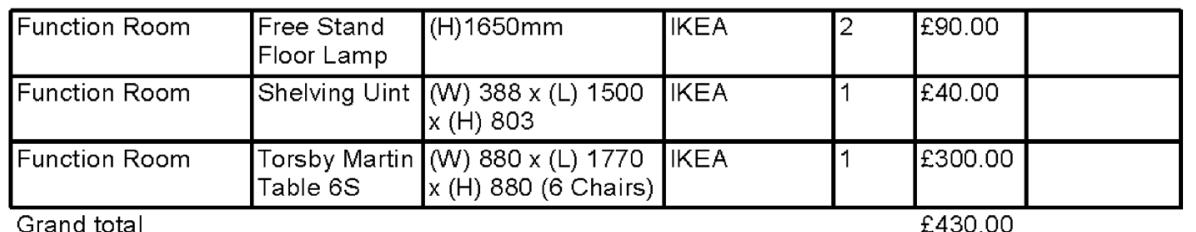

Fig. 4 Sample living room furniture schedule

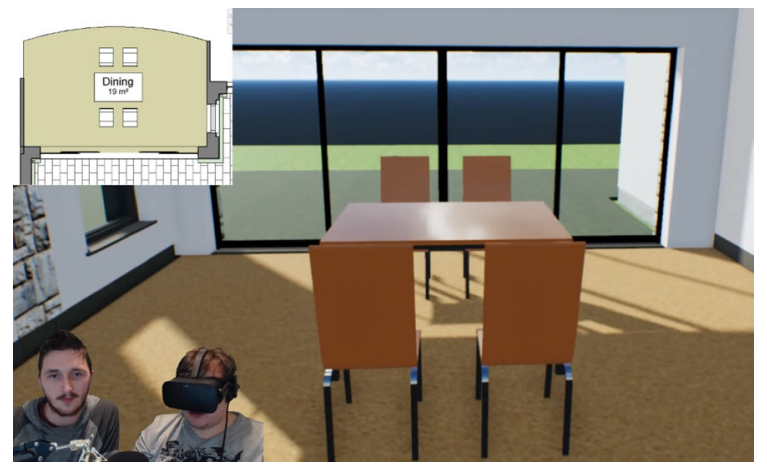

Fig. 5 Prototype tests showing changes in furniture

\section{Discussion and conclusions}

The goal of this research is to utilize existing technology in an original manner to achieve desirable outcomes; therefore, this paper is more practical rather than hypothetical in nature. This work details the ins and outs of the $\mathrm{B} / \mathrm{Q}$ documents and identifies a gap within the industry for which the present paper suggests a solution. The development strategy describes the proposed prototype and explains the reasons behind the choice to develop this

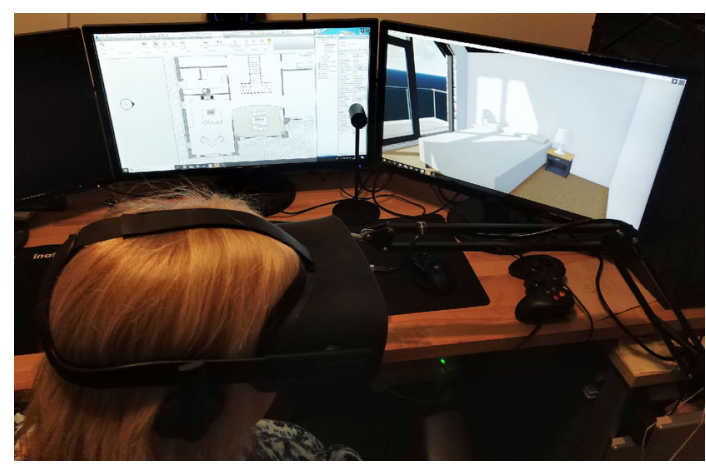

Fig. 6 Participant making changes within the VR

specific prototype, as well as the implications it may have on an architect's design choices. Existing products with similar features are also explored here.

The prototyping segment of the paper investigated all of the challenges involved in development and found those that were difficult to resolve. Instead of conducting risky and costly program development, the study instead opted to utilize existing technologies to produce the desired product. Details of the testing and demonstration processes, including images, schedule examples, and 
software/hardware, are also provided.

Overall, the Revit prototype was easily imported into Enscape, as the latter is a direct plugin for the former. The only issues this study experienced involved the setup of the live recordings as the study had to re-record the footage due to the number of software programs being used at once; this step proved to be a major setback. The tester for the prototype helped the researchers address issues within the experience that had to be altered to fit the needs of the client, such as the height of the user and the speed of the controller, to allow the client to be fully immersed without issue. This study found the direct inclusion using Enscape to be the best solution for accuracy for the $\mathrm{B} / \mathrm{Q}$ as it gives the client more control of their building.

Several enhancements can still be made to this method before it can be considered a gold standard. For example, an improved strategy that gives the client full access to the B/Q schedules within the VR headset may be implemented. This feature would allow the client to review costing within the headset and help them understand the cost of each change. At the moment, the developed prototype can only alter windows and furniture in real time, and these operations are done exclusively through Revit and the architect. For future versions of the solution, this limitation could be revised and improved so that the client can have some or full control. An advancement that could improve the user experience by reducing B/Q schedules to a more basic form so that clients can understand it better without the architect's explanation may be developed. The experiment presented in this study reduced windows and furniture as individual schedules and only within each room rather than providing a full overall cost. An additional improvement that updates window size costs, as well as component prices, during construction so that clients can see what extra costs may be entailed before windows are fitted would also be beneficial.

Open Access This article is licensed under a Creative Commons Attribution 4.0 International License, which permits use, sharing, adaptation, distribution and reproduction in any medium or format, as long as you give appropriate credit to the original author(s) and the source, provide a link to the Creative Commons license, and indicate if changes were made.

The images or other third party material in this article are included in the article's Creative Commons license, unless indicated otherwise in a credit line to the material. If material is not included in the article's Creative Commons license and your intended use is not permitted by statutory regulation or exceeds the permitted use, you will need to obtain permission directly from the copyright holder. To view a copy of this license, visit http:// creativecommons.org/licenses/by/4.0/.

\section{References}

Agency D (2018). IKEA Virtual Reality Showroom. Demodern Digitalagentur

Bandi S, Abdullah F, Amiruddin R (2014). Recapitulating the issues concerning the applications of the bills of quantities. International
Journal of Built Environment and Sustainability, 1(1): 63-70

Bille R, Smith S P, Maund K, Brewer G (2014). Extending Building Information Models into Game Engines. New York: ACM Press

Bouchlaghem D, Shang H, Whyte J, Ganah A (2005). Visualisation in architecture, engineering and construction (AEC). Automation in Construction, 14(3): 287-295

Chen S E (1995). Quicktime VR: An Image-based Approach to Virtual Environment Navigation. In: 22nd Annual Conference on Computer Graphics and Interactive Techniques, 29-38

Corke C (2017). Review: From Revit to VR. AEC Magazine, technology-mainmenu-35/1255

Davis P R, Love P E D, Baccarini D (2009). Bills of quantities: Nemesis or nirvana? Structural Survey, 27(2): 99-108

Donalek C, Djorgovski S G, Cioc A, Wang A, Zhang J, Lawler E, Yeh S, Mahabal A, Graham M, Drake A, Davidoff S, Norris J S, Longo G (2014). Immersive and Collaborative Data Visualization Using Virtual Reality Platforms. 2014 IEEE International Conference on Big Data, 609-614

Du J, Zou Z, Shi Y, Zhao D (2018). Zero latency: Real-time synchronization of BIM data in virtual reality for collaborative decision-making. Automation in Construction, 85: 51-64

JELD-WEN (2000). Interior and Exterior Doors, Windows, Patio Doors, Stairs. JELD-WEN

Laryea S (2011). Quality of tender documents: Case studies from the UK. Construction Management and Economics, 29(3): 275-286

Li H, Love P E D (1998). Visualization of Building Interior Design to Reduce Rework. IEEE Conference on Information Visualization, An International Conference on Computer Visualization and Graphics (Cat. No.98TB100246), 187-191

Lorenz M, Spranger M, Riedel T, Pürzel F, Wittstock V, Klimant P (2016). CAD to VR - A methodology for the automated conversion of kinematic CAD models to virtual reality. Procedia CIRP, 41:358363

Martínez-Rojas M, Marín N, Miranda M A V (2016). An intelligent system for the acquisition and management of information from bill of quantities in building projects. Expert Systems with Applications, 63: 284-294

Messner J I, Yerrapathruni S C, Baratta A J, Whisker V E (2003). Using Virtual Reality to Improve Construction Engineering Education. American Society for Engineering Education Annual Conference \& Exposition

Nadeem A, Wong A K, Wong F K W (2015). Bill of quantities with 3D views using building information modeling. Arabian Journal for Science and Engineering, 40(9): 2465-2477

Odeyinka H, Perera S (2009). An evaluation of the budgetary reliability of bills of quantities in building procurement. COBRA 2009, Royal Institution of Chartered Surveyors (RICS), London, UK, 435-446

Olatunji O A (2011). Virtual reality and estimating practice: A software selection model for estimating. Practice, 11: 13

Petrova E A, Rasmussen M, Jensen R L, Svidt K (2017). Integrating Virtual Reality and BIM for End-user Involvement in Building Design: A Case Study. The Joint Conference on Computing in Construction (JC3), 699-706

Rahimian F P, Chavdarova V, Oliver S, Chamo F (2019). OpenBIMTango integrated virtual showroom for offsite manufactured 
production of self-build housing. Automation in Construction, 102: $1-16$

Rashid R A, Mustapa M, Wahid S N A (2006). Bills of Quantities - Are they still useful and relevant today? International Conference on Construction Industry

Razali A, Tajudin A, Fadzli A (2014). Applicability of bill of quantities in construction procurement. International Journal of Engineering Science Invention, 3(7): 31-34

Shi Y, Du J, Lavy S, Zhao D (2016). A multiuser shared virtual environment for facility management. Procedia Engineering, 145: $120-127$

Sinclair D (2013). RIBA Plan of Work 2013 Overview. Royal Institute of British Architects, London, UK
Wang X, Schnabel M A (2008). Mixed Reality in Architecture, Design, and Construction. Berlin: Springer

Warwick K, Gray J O, Roberts D (1993). Institution of Electrical, Virtual reality in engineering. Institution of Electrical Engineers, ISBN 0 852968035

Weidlich D, Cser L, Polzin T, Cristiano D, Zickner H (2007). Virtual reality approaches for immersive design. CIRP Annals, 56(1): 139142

Zerolight L (2018). Zerolight. Available at Zerolight website on March 4, 2019

Zima K (2017). Impact of information included in the BIM on preparation of Bill of Quantities. Procedia Engineering, 208: 203210 